\title{
Analysis of the Sensitivity of Influencing Factors on Tunnel Secondary Lining Structure *
}

\author{
Kezhi Song \\ School of Civil Engineering Ludong University \\ Yantai, China \\ ytytskz@126.com
}

\author{
Yi Song \\ School of Civil Engineering Beijing Jiaotong University \\ Beijing, China
}

\author{
Liangji Kong \\ Yantai No.1 Middle School of Shandong \\ Yantai, China
}

\begin{abstract}
On the basis of the load-structure model and FEM and taking the secondary lining of the Qingdao-Rongcheng intercity railway tunnel as a research object, the sensitivity analysis of the influencing factors on the secondary lining's internal forces is conducted via the sensitivity coefficient method. The influencing factors are the elastic resistance coefficient of surrounding rock, the secondary lining thickness, the elastic modulus of secondary lining, and the lateral pressure coefficient, whose values are taken from the engineering practice. The analysis result shows that (1) to crown bending moment, the descending order of the sensitivities of the influencing factors are secondary lining thickness, elastic resistance coefficient of surrounding rock, lateral pressure coefficient, and elastic modulus of secondary lining; (2) to crown axial force, the descending order is lateral pressure coefficient, elastic resistance coefficient of surrounding rock, secondary lining thickness, and elastic modulus of secondary lining; (3) to crown vertical displacement, the descending order is elastic resistance coefficient of surrounding rock, secondary lining thickness, lateral pressure coefficient, and elastic modulus of secondary lining; and (4) for the safety factor of the crown cross section, the descending order is elastic resistance coefficient of surrounding rock, lateral pressure coefficient, secondary lining thickness, and elastic modulus of secondary lining.
\end{abstract}

Keywords - tunnel engineering;sensitivity analysis; secondary lining; influencing factor

\section{INTRODUCTION}

Presently, tunnel secondary linings in China are designed according to two codes: Specifications for design of highway tunnel (JTG D70-2004) ${ }^{[1]}$ and Specifications for design of railway tunnel (TB10003-2005) ${ }^{[2]}$. The method of designing a secondary lining is explained in items 9.2.1 and 9.2.2 in the highway tunnel specification ${ }^{[1]}$. The load-structure method should be employed in designing the integral lining of a deep tunnel, the integral lining or combined lining in a shallow tunnel, and the open cut tunnel lining. The secondary lining of a deep tunnel can also be designed by the load-structure method. In this method, secondary lining forces will be affected by the following factors: the elastic resistance coefficient of surrounding rock, the lateral pressure coefficient,

Supported by the Natural Science Foundation of Province Shandong (No.ZR2012EEL27) and the Natural Science Foundation of China (No.51278237). the thickness of the secondary lining, and the elastic modulus of the secondary lining when the surrounding pressure is symmetric. The influences of the elastic resistance coefficient of surrounding rock on the safety coefficient and in controlling bending moment are analyzed for a single-line railway tunnel by $\mathrm{LU}^{[3]}$. The influence of the elastic resistance coefficient of surrounding rock on crown axial force, bottom axial force, crown bending moment, and arch shoulder bending moment are analyzed in a double-line railway tunnel by LI, ZHANG, and $\mathrm{ZHAO}^{[4]}$. The influence of the elastic resistance coefficient of surrounding rock on secondary lining internal forces in all kinds of cases are analyzed based on the loadstructure method (solved by FEM) by SONG and WANG ${ }^{[5]}$. The lining safety of highway tunnels is assessed by analysis of internal forces, the safety coefficient, convergence displacement, crown settlement, and the plastic zone distribution of surrounding $\operatorname{rock}^{[6]}$. The mechanical characteristics of preliminary bracing and secondary lining in different construction stages in a highway tunnel are tested by $\mathrm{ZHAO}^{[7]}$ and $\mathrm{Xu}^{[8]}$. The mechanical characteristics of the preliminary bracing and the secondary lining in the condition of high ground stress are analyzed by JIN and LI ${ }^{[9]}$, providing a basis for lining structure design and stability assessment of deep tunnels in high ground stress area. The stability of surrounding rock in a deep tunnel is analyzed by field testing data, the chaotic dynamics of the tunnel system are analyzed qualitatively, and variation laws of different variables in the tunnel system are well predicted ${ }^{[10]}$. The above research results suggest that design and construction of a tunnel are often affected by multiple factors. We need to recognize the importance of these factors because they will have an important guiding effect for improving and optimizing a tunnel design. Research into the challenge of designing a tunnel secondary lining is relatively lacking. As a method, sensitivity analysis is often used to investigate factors that influence a variable, such as bridge structures and road structures in traffic civil engineering ${ }^{[11-12]}$. The importance of influencing factors on tunnel secondary lining will be explored in this paper.

\section{PRinciple of Sensitivity ANAlysis}

An investigated index $Y$ can be considered as a function of $n$ influencing factors; that is, 


$$
Y=f\left(X_{1}, X_{2}, X_{3}, \ldots, X_{\mathrm{n}}\right)
$$

But in mechanical analysis of tunnel structure, formula (1) is only a mathematical function. It cannot be expressed by a finite function.

So, in order to analyze the influencing degree of the $i$ th factor, we define its sensitivity degree as

$$
\begin{gathered}
S_{i}=\frac{\eta_{1}}{\eta_{2}} \\
\eta_{1}=\frac{\left|\Delta Y_{j}\right|}{Y_{j 0}} \\
\eta_{2}=\frac{\left|\Delta X_{i}\right|}{X_{i, \max }-X_{i, \min }}
\end{gathered}
$$

where, $\Delta X_{i}$ is the variation of the factor $X_{i}, \Delta X_{i}=X_{i}-X_{i 0}, \boldsymbol{X}_{i 0}$ is the reference value of $X_{\mathrm{i}}$, and $X_{i, \max }$ and $X_{i, \min }$ are the maximum value and minimum value of $X_{i}$, respectively; $Y_{j 0}$ is reference value of an index based on the reference value of every factor, and $\Delta Y_{j 0}$ is variation of an investigated index $Y_{j}$ caused by variation of a factor; and $\eta_{1}$ is the change rate of an investigated index $Y_{j}$ caused by variation of the factor $X_{i}$, and $\eta_{2}$ is the change rate of a factor $X_{i}$. Thus the sensitivity degree of a factor is defined as the ratio of variation of $Y_{i}$ and variation of $X_{i}$. If a small-amplitude variation of a factor can lead to great changes of an index, the sensitivity degree of the factor is great and the factor is sensitive.

Based on these equations, a program that performs sensitivity analysis can be developed. First, a reference set of the tunnel parameters is confirmed by means of in situ tests or engineering analogy, and mechanic characteristics are solved by FEM based on the load-structure model. Then parameters of a factor are changed near its reference value in accordance with engineering practice while other factors are held constant. The internal forces of the tunnel lining are then calculated with the changing parameters. Finally, the sensitivity degree of all factors for the mechanical index can be determined successively by formula (2).

\section{TunNel ENGINEERING GEOLOGY AND Linging StRUCTURE}

The Zhenshan tunnel in the Qing-Rong (QingdaoRongcheng) intercity railway is located in the city of Yantai; with a length of $5510.0 \mathrm{~m}$, it is a key feat of engineering for the whole railway. The formation lithology of the tunnel from ground to depth are: (1) Silty clay, fine sand, medium-coarse sand; (2) Schist and granulite, biotite granulite with graphite, tremolite with graphite and biotite schist; (3) Gneissic finegrained biotite adamellite, granite pegmatite. The surrounding levels are III-V; the tunnel's classification of geotechnical engineering construction is listed in table 1 .

The construction clearance of Zhenshan tunnel was submitted to the Construction clearance passenger dedicated railway line in Design temporary provisions for new passenger dedicated railway line of 200-250 km/h (Railway construction [2007] No.1140). The net cross section area of the top of the tunnel is $81.37 \mathrm{~m}^{2}$. A combined lining is adopted in the section of covered digging, but the tunnel's standard

\begin{tabular}{|c|c|c|}
\hline $\begin{array}{c}\text { Formation } \\
\text { lithology }\end{array}$ & $\begin{array}{c}\text { Degree of } \\
\text { weathering } \\
\text { and dense } \\
\text { degree } \\
\end{array}$ & $\begin{array}{l}\text { Classification for } \\
\text { construction of } \\
\text { rock and soil } \\
\text { engineering }\end{array}$ \\
\hline Silty clay & Hard plastic & \\
\hline \multirow{3}{*}{ Schist } & W4 & III \\
\hline & W3 & IV \\
\hline & W2 & V \\
\hline \multirow{3}{*}{ Granulite } & W4 & III \\
\hline & W3 & IV \\
\hline & W2 & V \\
\hline \multirow{3}{*}{ Marble } & W4 & III \\
\hline & W3 & IV \\
\hline & W2 & V \\
\hline \multirow{3}{*}{$\begin{array}{l}\text { Gneissic fine- } \\
\text { grained biotite } \\
\text { adamellite }\end{array}$} & W4 & III \\
\hline & W3 & IV \\
\hline & W2 & V \\
\hline Fault breccia & & IV \\
\hline
\end{tabular}
cross section is shown in figure 1 .

TABLE I. ClassficATION OF GEOLOGICAL ENGINEERING CONSTRUCTION FOR ZHENSHAN TUNNEL

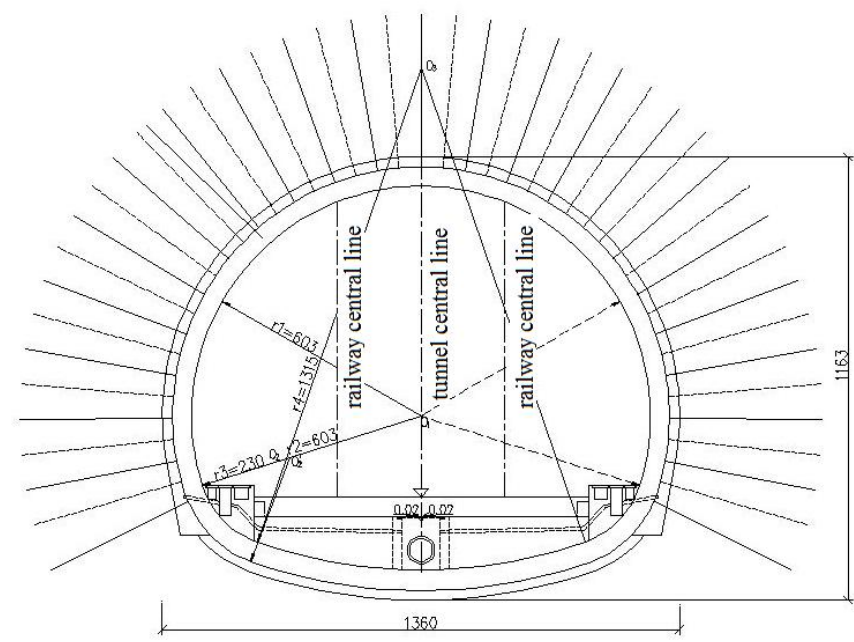

Fig. 1. Standard Cross Section of Zhenshan Tunnel(unit: $\mathrm{cm}$ )

\section{Calculation Method and Values of Influence FACTORS}

\section{A. Load and Structure Calculation}

Considering the load case of a deep-buried tunnel, its surrounding rock pressure is suggested to be loose pressure, obtained by tests and code equation.

\section{1) Design code equation}

The surrounding rock pressure is calculated according to the first and second section of item 4.3.3 in the code ${ }^{[2]}$. 
2) Tests for contact pressure of surrounding rock

Ten days after the concrete pouring of the secondary lining was completed, the surrounding rock pressure was tested on March 26, 2013, for the cross section of DK210 + 55 in Zhenshan tunnel (figure 2). Its contact pressure is shown in figure 3 .

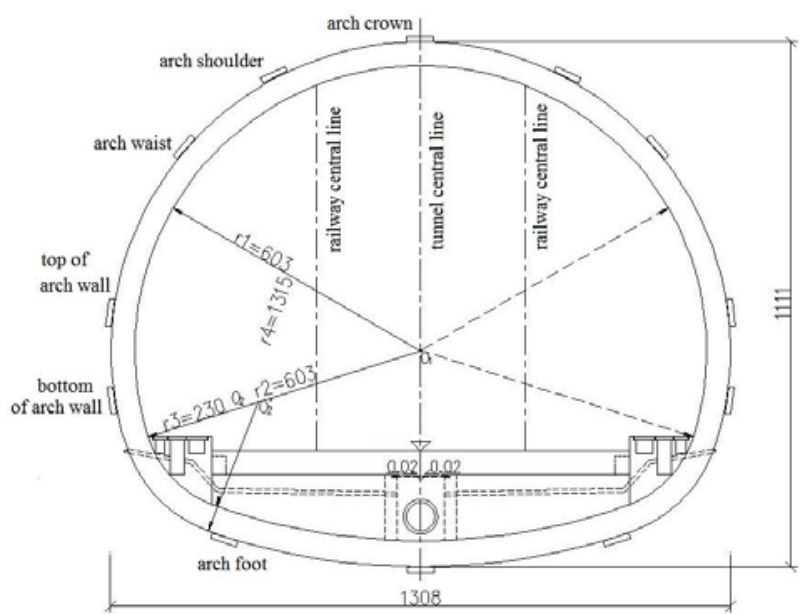

Fig. 2. Distribution of Measuring Points for Contact Pressure of Surrounding Rock(unit: $\mathrm{cm}$ )

Ten days after the concrete pouring of the secondary lining was completed, the surrounding rock pressure was tested on March 26, 2013, for the cross section of DK210 + 55 in Zhenshan tunnel (figure 2). Its contact pressure is shown in figure 3 .

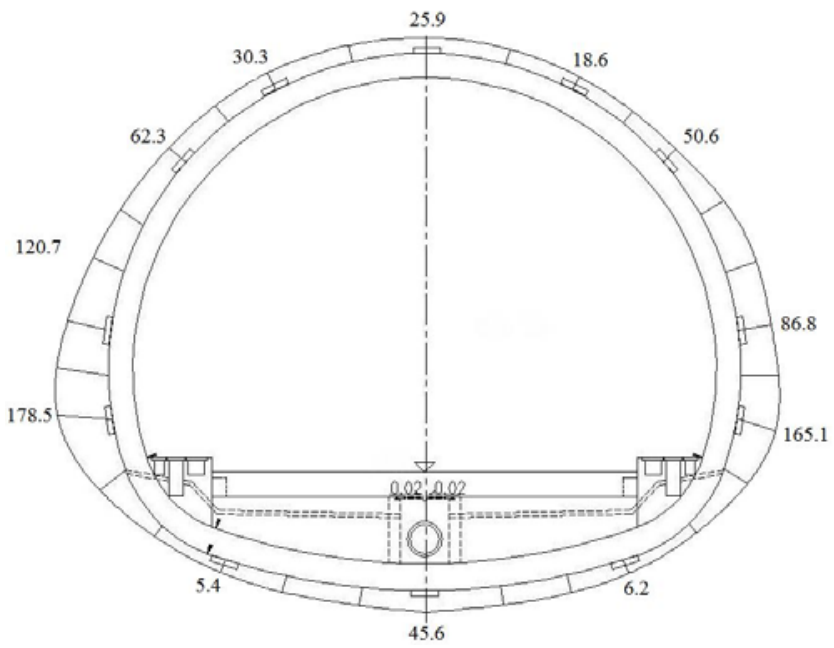

Fig. 3. Distribution of Contact Pressure along Tunnel Arch Ring(unit: kPa)

\section{3) Lining structure calculation}

Based on the load-structure model, mechanical analysis of the secondary lining is carried out by FEM of MIDAS/GTS in different cases; its model is shown as figure 4. Within this model, the secondary lining is simulated with a beam element, and ground reaction force surrounding the lining is simulated with a spring element. Regarding the uncoupling in arch crown, compression spring elements are considered and tensile spring elements are not allowed.

The safety coefficient $K$ of the secondary lining is calculated using equations (11.2.1) and (11.2.2) in the code ${ }^{[2]}$.

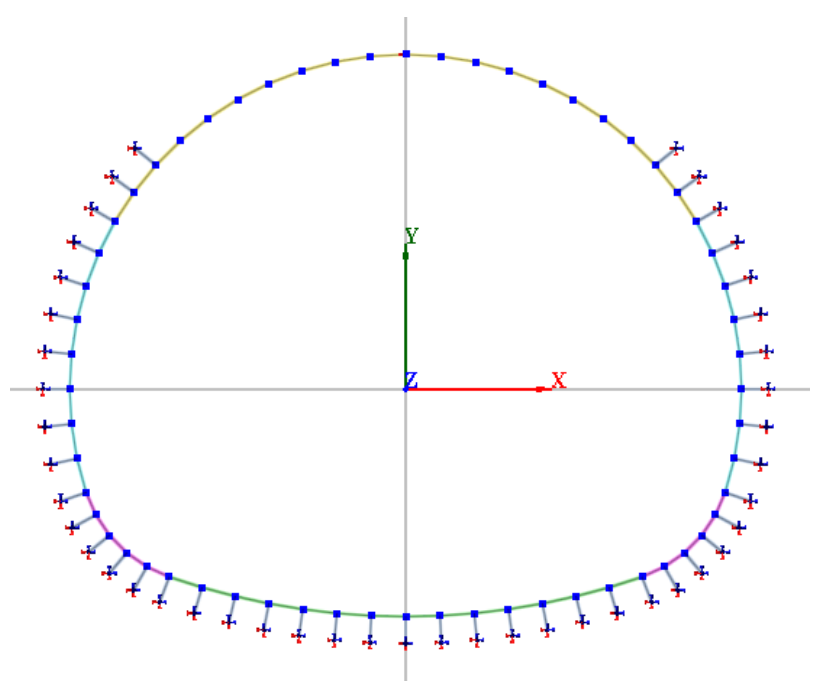

Fig. 4. Load-structure model based on MIDAS/GTS

\section{B. Influencing Factors and Parameters Selection}

During the analysis, four factors are taken into account: elastic resistance coefficient, thickness of secondary lining, elastic modulus of secondary lining, and lateral pressure coefficient. Possible values of the factors in the engineering practice are listed in table 2; the values for row number 3 are the reference parameters of the factors. The parameters in table 2 are used in FEM analysis.

TABLE II. VALUES OF INFLUENCE FACTORS

\begin{tabular}{|c|c|c|c|c|}
\hline $\begin{array}{c}\text { Order } \\
\text { number }\end{array}$ & $\begin{array}{c}\text { Elastic } \\
\text { resistance } \\
\text { coefficient/ } \\
\left(\times \mathbf{1 0}^{\mathbf{5}}\right. \\
\left.\mathbf{k N} \cdot \mathbf{m}^{-3}\right)\end{array}$ & $\begin{array}{c}\text { Thickness } \\
\text { of } \\
\text { secondary } \\
\text { lining }(\mathbf{m})\end{array}$ & $\begin{array}{c}\text { Elastic } \\
\text { modulus of } \\
\text { secondary } \\
\text { lining } \\
\left(\times \mathbf{1 0}^{\mathbf{7}} \mathbf{k N} \cdot \mathbf{m}^{-\mathbf{2}}\right)\end{array}$ & $\begin{array}{c}\text { Lateral } \\
\text { pressure } \\
\text { coefficient }\end{array}$ \\
\hline 1 & 0.5 & 0.35 & 2.80 & 0.1 \\
\hline 2 & 1.0 & 0.4 & 2.95 & 0.2 \\
\hline 3 & 1.5 & 0.45 & 3.10 & 0.3 \\
\hline 4 & 2.0 & 0.5 & 3.35 & 0.4 \\
\hline 5 & 2.5 & 0.55 & 3.55 & 0.5 \\
\hline
\end{tabular}

\section{Calculation Method and Values of Influence FACTORS}

\section{A. Calculation results based on reference parameters}

The bending moment and axial force of the secondary lining based on the reference parameters are shown as figure 5 .

From figure 5, the maximum positive bending moment and the maximum negative bending moment under calculating loads exist on the arch crown and arch shoulder, respectively; they are $72.3 \mathrm{kN} \cdot \mathrm{m}$ and $-92.5 \mathrm{kN} \cdot \mathrm{m}$, respectively. There are larger positive or negative bending moments at the arch 
bottom and arch foot, but they don't generally play a role. Axial forces caused by loads in the secondary lining are all compression force. They increase from the crown to the bottom gradually; the crown value is $442.9 \mathrm{kN}$ and the foot value is $954.4 \mathrm{kN}$. According to the load calculations, the arch crown is in a state of eccentric compression; its safety coefficient therefore is minor due to its superior bending moment and minor axial force.

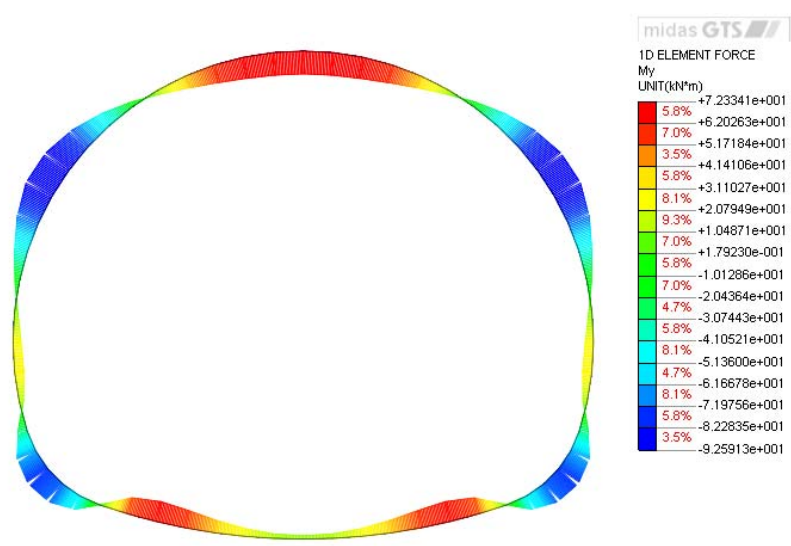

(a) Figure of bending moment (unit: $\mathrm{kN} \cdot \mathrm{m}$ )

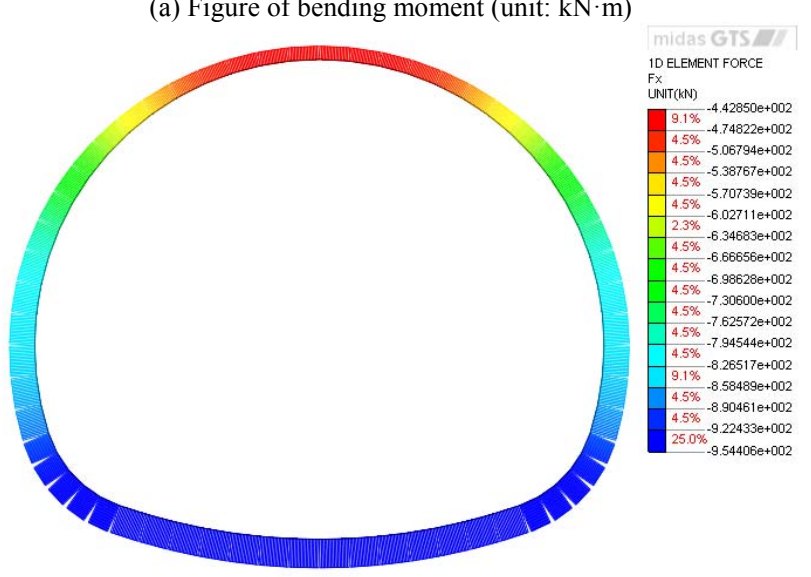

(b) Figure of axial force (unit: $\mathrm{kN}$ )

Fig. 5. Nephograms of internal force of secondary lining based on reference parameters

\section{B. Sensitivity of the influencing factors}

1) Force indexes of secondary lining at different parameters of the factors

According to the mechanical characteristics of the secondary lining, four indexes are investigated: bending moment of crown, axial force of crown, vertical displacement of crown, and safety factor of crown cross section. The results of FEM analysis of different levels of influencing factors are listed in table 3 .

From table 3, the bending moment of the arch crown clearly decreases with the increase of the elastic resistance coefficient of surrounding rock and lateral pressure coefficient, but increases with the increase of secondary lining thickness and elastic modulus of secondary lining. The axial force of the arch crown increases with an increasing elastic resistance coefficient of surrounding rock and lateral pressure coefficient, but decreases with an increasing of secondary lining thickness and elastic modulus of secondary lining. The safety coefficient of the arch crown cross section increases with the increasing of the elastic resistance coefficient of surrounding rock, elastic modulus of secondary lining, and lateral pressure coefficient, decreasing only with the increasing of secondary lining thickness. However, as the elastic resistance coefficient of surrounding rock increases, secondary lining thickness, elastic modulus of secondary lining, lateral pressure coefficient, and vertical displacement of arch crown all decrease.

TABLE III. FORCE INDEXES OF SECONDARY LINING IN DIFFERENT LEVELS OF INFLUENCING FACTORS*

\begin{tabular}{|c|c|c|c|c|c|}
\hline \multicolumn{2}{|c|}{ Factor Index } & $\begin{array}{c}\text { Bending } \\
\text { moment } \\
\text { of crown } \\
(\mathrm{kN} \cdot \mathrm{m}) \\
\end{array}$ & $\begin{array}{c}\text { Axial } \\
\text { force of } \\
\text { crown } \\
(\mathbf{k N}) \\
\end{array}$ & $\begin{array}{l}\text { Vertical } \\
\text { displacement } \\
\text { of crown } \\
(\mathbf{m m})\end{array}$ & $\begin{array}{l}\text { Safety } \\
\text { factor }\end{array}$ \\
\hline \multirow{5}{*}{$\begin{array}{l}\text { Elastic } \\
\text { resistance } \\
\text { coefficient }\end{array}$} & 0.5 & 118.1 & 415.7 & 12.25 & 1.49 \\
\hline & 1.0 & 85.8 & 434.2 & 7.55 & 2.44 \\
\hline & 1.5 & 72.3 & 442.9 & 5.87 & 3.32 \\
\hline & 2.0 & 63.7 & 449.1 & 4.96 & 4.33 \\
\hline & 2.5 & 58.0 & 453.3 & 4.41 & 5.41 \\
\hline \multirow{5}{*}{$\begin{array}{l}\text { Thickness } \\
\text { of } \\
\text { secondary } \\
\text { lining }\end{array}$} & 0.35 & 44.6 & 449.8 & 6.63 & 4.28 \\
\hline & 0.4 & 56.5 & 446.7 & 6.20 & 3.84 \\
\hline & 0.45 & 72.3 & 442.9 & 5.87 & 3.32 \\
\hline & 0.5 & 87.7 & 440.5 & 5.57 & 3.15 \\
\hline & 0.55 & 104.2 & 437.9 & 5.33 & 3.03 \\
\hline \multirow{5}{*}{$\begin{array}{c}\text { Elastic } \\
\text { modulus } \\
\text { of } \\
\text { secondary } \\
\text { lining }\end{array}$} & 2.80 & 69.1 & 445.2 & 6.11 & 2.81 \\
\hline & 2.95 & 70.7 & 444.0 & 5.98 & 3.16 \\
\hline & 3.10 & 72.3 & 442.9 & 5.87 & 3.32 \\
\hline & 3.35 & 74.9 & 441.1 & 5.69 & 3.81 \\
\hline & 3.55 & 76.7 & 440.0 & 5.56 & 4.19 \\
\hline \multirow{5}{*}{$\begin{array}{c}\text { Lateral } \\
\text { pressure } \\
\text { coefficient }\end{array}$} & 0.1 & 88.9 & 415.1 & 6.44 & 2.25 \\
\hline & 0.2 & 80.6 & 429.0 & 6.15 & 2.68 \\
\hline & 0.3 & 72.3 & 442.9 & 5.87 & 3.32 \\
\hline & 0.4 & 62.9 & 458.3 & 5.55 & 4.55 \\
\hline & 0.5 & 60.9 & 474.0 & 5.22 & 5.13 \\
\hline
\end{tabular}

The units of the factors are the same as in TABLE I.

2) Calculation for the sensitivities of the influencing factors

According to the results of FEM analysis of the value levels of the factors, the sensitivity degrees of the factors influencing the indexes can be calculated by means of equations (2), (3), and (4); the results are listed in tables 4 to 7.

TABLE IV. Sensitivities of CROWN Bending Moment

\begin{tabular}{|c|c|c|c|c|c|}
\hline $\begin{array}{c}\text { Elastic resistance } \\
\text { coefficient } \\
\left(\times 10^{5} \mathrm{kN} \cdot \mathrm{m}^{-3}\right) \\
\end{array}$ & 0.5 & 1 & 2 & 2.5 & $\sum S$ \\
\hline Sensitivity $S$ & 1.2669 & 0.7469 & 0.4758 & 0.3956 & 2.8852 \\
\hline $\begin{array}{c}\text { Thickness of secondary } \\
\text { lining (m) }\end{array}$ & 0.35 & 0.4 & 0.5 & 0.55 & $\sum S$ \\
\hline Sensitivity $S$ & 0.7663 & 0.8741 & 0.852 & 0.8824 & 3.3748 \\
\hline $\begin{array}{c}\text { Elastic modulus of } \\
\text { secondary lining } \\
\left(\times 10^{7} \mathrm{kN} \cdot \mathbf{m}^{-2}\right)\end{array}$ & 2.8 & 2.95 & 3.35 & 3.55 & $\sum S$ \\
\hline Sensitivity $S$ & 0.1107 & 0.1107 & 0.1079 & 0.1014 & 0.4306 \\
\hline $\begin{array}{c}\text { Lateral pressure } \\
\text { coefficient }\end{array}$ & 0.1 & 0.2 & 0.4 & 0.5 & $\sum S$ \\
\hline Sensitivity $S$ & 0.4592 & 0.4592 & 0.5201 & 0.3154 & 1.7538 \\
\hline
\end{tabular}


TABLE V. SENSITIVITIES OF CROWN AXIAL ForCE

\begin{tabular}{|c|c|c|c|c|c|}
\hline $\begin{array}{c}\text { Elastic resistance } \\
\text { coefficient } \\
\left(\times 10^{5} \mathrm{kN} \cdot \mathrm{m}^{-3}\right)\end{array}$ & 0.5 & 1 & 2 & 2.5 & $\sum S$ \\
\hline Sensitivity $S$ & 0.1228 & 0.0786 & 0.056 & 0.028 & 0.2854 \\
\hline $\begin{array}{c}\text { Thickness of } \\
\text { secondary lining } \\
(\mathrm{m})\end{array}$ & 0.35 & 0.4 & 0.5 & 0.55 & $\Sigma S$ \\
\hline Sensitivity $S$ & 0.0312 & 0.0343 & 0.0217 & 0.0226 & 0.1097 \\
\hline  & 2.8 & 2.95 & 3.35 & 3.55 & $\sum S$ \\
\hline Sensitivity $S$ & 0.013 & 0.0124 & 0.0122 & 0.0109 & 0.0485 \\
\hline $\begin{array}{c}\text { Lateral pressure } \\
\text { coefficient }\end{array}$ & 0.1 & 0.2 & 0.4 & 0.5 & $\Sigma S$ \\
\hline Sensitivity $S$ & 0.1255 & 0.1255 & 0.1391 & 0.1404 & 0.5306 \\
\hline
\end{tabular}

TABLE Vi. Sensitivities of Crown Vertical Displacement

\begin{tabular}{|c|c|c|c|c|c|}
\hline $\begin{array}{c}\text { Elastic resistance } \\
\text { coefficient } \\
\left(\times 10^{5} \mathrm{kN} \cdot \mathrm{m}^{-3}\right) \\
\end{array}$ & 0.5 & 1 & 2 & 2.5 & $\Sigma S$ \\
\hline Sensitivity $S$ & 2.1738 & 1.1448 & 0.6201 & 0.3101 & 4.2487 \\
\hline $\begin{array}{c}\text { Thickness of } \\
\text { secondary lining } \\
(\mathbf{m})\end{array}$ & 0.35 & 0.4 & 0.5 & 0.55 & $\Sigma S$ \\
\hline Sensitivity $S$ & 0.2589 & 0.2249 & 0.2044 & 0.184 & 0.8722 \\
\hline 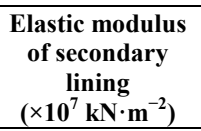 & 2.8 & 2.95 & 3.35 & 3.55 & $\Sigma S$ \\
\hline Sensitivity $S$ & 0.1022 & 0.0937 & 0.092 & 0.088 & 0.3759 \\
\hline $\begin{array}{c}\text { Lateral pressure } \\
\text { coefficient }\end{array}$ & 0.1 & 0.2 & 0.4 & 0.5 & $\Sigma S$ \\
\hline Sensitivity $S$ & 0.1942 & 0.1908 & 0.2181 & 0.2215 & 0.8245 \\
\hline
\end{tabular}

TABLE VII. SENSITIVITIES OF SAFETy FACtor OF Crown Cross SECTION

\begin{tabular}{|c|c|c|c|c|c|}
\hline $\begin{array}{c}\text { Elastic resistance } \\
\text { coefficient } \\
\left(\times 10^{5} \mathrm{kN} \cdot \mathrm{m}^{-3}\right)\end{array}$ & 0.5 & 1 & 2 & 2.5 & $\Sigma S$ \\
\hline Sensitivity $S$ & 1.1024 & 1.0602 & 2.4217 & 1.259 & 5.8434 \\
\hline $\begin{array}{c}\text { Thickness of } \\
\text { secondary lining } \\
(\mathrm{m})\end{array}$ & 0.35 & 0.4 & 0.5 & 0.55 & $\Sigma S$ \\
\hline Sensitivity $S$ & 0.5783 & 0.6265 & 0.2048 & 0.1747 & 1.5843 \\
\hline $\begin{array}{c}\text { Elastic modulus } \\
\text { of secondary } \\
\text { lining } \\
\left(\times 10^{7} \mathbf{k N} \cdot \mathbf{m}^{-2}\right) \\
\end{array}$ & 2.8 & 2.95 & 3.35 & 3.55 & $\Sigma S$ \\
\hline Sensitivity $S$ & 0.384 & 0.241 & 0.4428 & 0.4367 & 1.5045 \\
\hline $\begin{array}{c}\text { Lateral pressure } \\
\text { coefficient }\end{array}$ & 0.1 & 0.2 & 0.4 & 0.5 & $\Sigma S$ \\
\hline Sensitivity $S$ & 0.6446 & 0.7711 & 1.4819 & 1.0904 & 3.988 \\
\hline
\end{tabular}

The four indexes - bending moment of arch crown, axial force of arch crown, vertical displacement of arch crown, and safety coefficient of arch crown-are numbered 1 to 4 successively. The four factors of elastic resistance coefficient of surrounding rock, secondary lining thickness, elastic modulus of secondary lining, and lateral pressure coefficient are similarly numbered 1 to 4 . Comprehensive values for sensitivities of the factors are extracted from tables 4 through 7. Curves of the relation between sensitivities and influencing factors are plotted in figure 6, and curves of the sensitivities varying with the investigated force indexes are plotted in figure 7 .

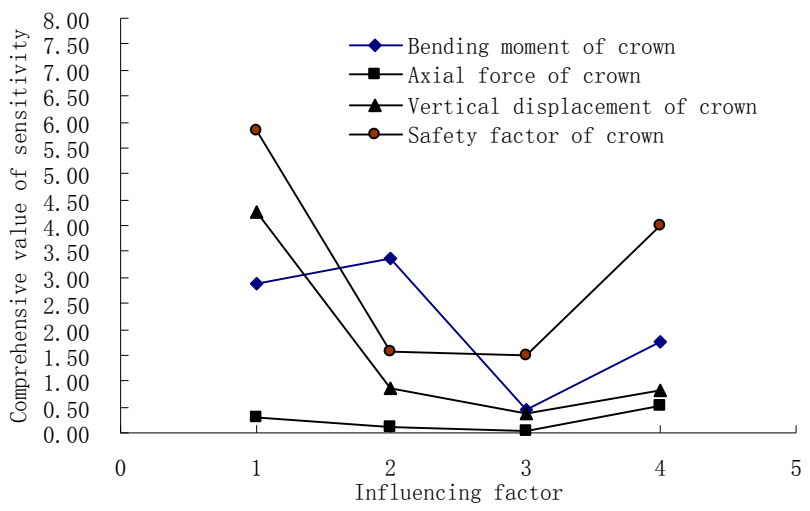

Fig. 6. Relationship between sensitivity and influencing factors



Fig. 7. Relationship between sensitivity and force indexes

Comparing tables 4 to 7 with figures 6 and 7 synthetically, in four factors, sensitivities of elastic modulus of secondary lining are minor for every index; in four indexes, axial force of crown is influenced indistinctively by every factor. In other cases, sensitivity degrees of other factors differ greatly for different indexes. To the crown-bending moment, the descending order of the sensitivities of the influencing factors are secondary lining thickness, elastic resistance coefficient of surrounding rock, lateral pressure coefficient, and elastic modulus of secondary lining. For crown axial force, the descending order is lateral pressure coefficient, elastic resistance coefficient of surrounding rock, secondary lining thickness, and elastic modulus of secondary lining. In the case of crown vertical displacement, the descending order is elastic resistance coefficient of surrounding rock, secondary lining thickness, lateral pressure coefficient, and elastic modulus of secondary lining. Regarding the safety factor of the crown cross section, the descending order is elastic resistance coefficient of surrounding rock, lateral pressure coefficient, secondary lining thickness, and elastic modulus of secondary lining. 


\section{CONCLUSIONS}

Based on the load structure model and FEM, sensitivity analysis of influence factors on secondary lining internal forces is performed according to the sensitivity coefficient method. For engineering background, the tunnel secondary lining of the $200 \mathrm{~km} / \mathrm{h}$ Qing-Rong intercity railway is introduced. Four influence factors and four indexes are considered. The following conclusions are reached.

(1) Comparing four factors, elastic modulus of secondary lining affects every investigated index lightly; comparing four indexes, axial force of crown is influenced indistinctively by every factors.

(2) To crown bending moment, sensitivity of secondary lining thickness is maximum, and the descending order of the other influencing factors are elastic resistance coefficient of surrounding rock, lateral pressure coefficient, and elastic modulus of secondary lining. Crown bending moment has negative correlation with elastic resistance of surrounding rock and lateral pressure coefficient, but has positive correlation with secondary lining thickness and elastic modulus of secondary lining.

(3) To crown axial force, sensitivity of lateral pressure coefficient is maximum, and the descending order of the other influencing factors are elastic resistance coefficient of surrounding rock, secondary lining thickness, and elastic modulus of secondary lining. Crown axial force has positive correlation with elastic resistance of surrounding rock and lateral pressure coefficient, but has negative correlation with secondary lining thickness and elastic modulus of secondary lining.

(4) To crown vertical displacement, sensitivity of elastic resistance coefficient of surrounding rock is maximum, and the descending order of the other influencing factors are secondary lining thickness, lateral pressure coefficient, and elastic modulus of secondary lining. Crown vertical displacement has negative correlation with all four considered factors.

(5) To crown safety coefficient, sensitivity of elastic resistance coefficient of surrounding rock is maximum, and the descending order of the other influencing factors are lateral pressure coefficient, secondary lining thickness, and elastic modulus of secondary lining. Crown safety coefficient has positive correlation with elastic resistance of surrounding rock, elastic modulus of secondary lining, and lateral pressure coefficient, but has negative correlation with secondary lining thickness.

\section{REFERENCES}

[1] Chongqing communications research and Design Institute, Code for Design of Road Tunnel(JTG D70-2004), Beijing: China communication press, 2004, pp.28-30.

[2] Second survey and Design Institute of the Ministry of Railways, Code for Design on Tunnel of Railway Tunnel (TB10003-2005), Beijing: China railway press, 2005, pp.31-35.

[3] LU Meili, Analysis on Influencing Factors for Internal Force of Railway Tunnel Lining, Tunnel Construction, Luoyang, Vol. 29(1), 2009, pp.3337.

[4] LI Pengfei, ZHANG Dingli, ZHAO Yong, ZHOU Ye, FANG Qian, ZHANG Xuan, Study of Mechanical Characteristics of Secondary Lining of Large-section Loess tunnel, Chinese Journal of Rock Mechanics and Engineering, Wuhan, Vol. 29(8), 2010, PP.1690-1696. (in Chinese)

[5] SONG Kezhi, WANG Mengshu, Influence of Elastic Resistance of Wall Rock on Tunnel Lining Internal Forces, Hydrageology and Engineering Geology, Beijing, Vol. 40(1), 2013, pp. 79-82.

[6] CHEN Jianxun, OUYANG Yuanping, WANG Mingnian, Numerical Computing and Analysis of highway Tunnel Composite Lining Structure, China Journal of Highway and Transport, Xian, Vol. 19(2), 2006, pp: 74-79.

[7] ZHAO Zhanchang, XIE Yongli, YANG Xiaohua, LI Youyun, Observation Research on the Mechanical Characteristic of Highway Tunnel Lining in Loess, China Journal of Highway and Transport, Beijing, Vol. 17(1), 2004, pp. 66-69.

[8] XU Linsheng, Mechanical Monitoring and Analysis on Composite Lining Structure of Highway Tunnel with Large Cross section, Journal of Chongqing Jiaotong University: Natural Science Edition, Chongqing, Vol. 28(3), 2009, pp. 528-530.

[9] JIN Xiaoguang, LI Xiaohong, Study on Mechanical Properties of Support Structure of Deep Buried Tunnel Soft and Weak Surrounding Rock in High Situ Stress Area, Journal of Highway and Transportation Research and Development, Beijing, Vol. 25(2), 2008, pp. 101-105.

[10] ZHAO Yu, PENG Haiyou, LU Yiyu, Study on Nonlinear Dynamic Character of Interaction between Surrounding Rock and Support Structure of Deep Buried Tunnel, Journal of Highway and Transportation Research and Development, Beijing, Vol. 26(11), 2009, pp. 98-102.

[11] ZHAO Xiaohua, SUN Hang, ZHANG Xiedong, PAN Bo, Sensitivity of Structural Parameters of PC Girder Bridge to Mechanical Property at Maximum Cantilever Stage, Journal of Highway and Transportation Research and Development, Beijing, Vol. 28(11), 2011, pp. 95-99.

[12] WEI Daoxin. Sensitivity Analysis of Asphalt Pavement Structure Responses under Multi-wheel Loads, Journal of Highway and Transportation Research and Development, Beijing, Vol. 27(12), 2010, pp. 21-27. 